\title{
ThI/ThI7 Cytokine Profiles are Associated with Disease Severity and Exacerbation Frequency in COPD Patients
}

This article was published in the following Dove Press journal:

International Journal of Chronic Obstructive Pulmonary Disease

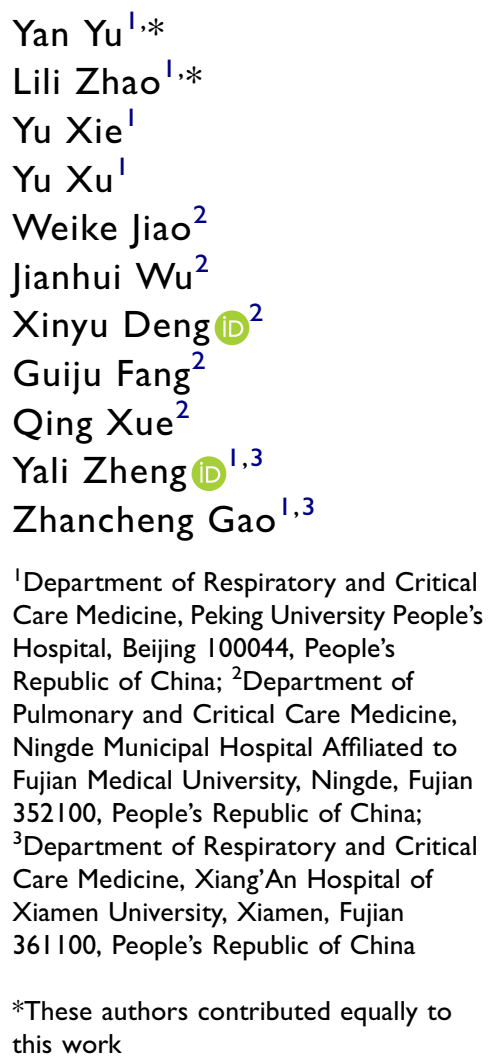
this work

\begin{abstract}
Background: $\mathrm{T}$ helper $(\mathrm{Th})$ cell cytokine imbalances have been associated with the pathophysiology of chronic obstructive pulmonary disease (COPD), including the Th1/Th2 and Th17/T regulatory cells (Treg) paradigms. Clarifying cytokine profiles during COPD acute exacerbation (AE) and their relationships with clinical manifestations would help in understanding the pathogenesis of disease and improve clinical management.
\end{abstract}

Materials and Methods: Eighty seven patients admitted to the hospital with AEs of COPD were included in this study, and follow-up was conducted after discharge (every 30 days, for a total of 120 days). Sputum samples of patients at different time points (including at admission, discharge, and follow-up) were collected, and sputum cytokine profiling (12 cytokines in total) was performed using a Luminex assay.

Results: According to the cytokine profiles at admission, patients were divided into three clusters by a $k$-means clustering algorithm, namely, Th1 $1_{\text {high }} \operatorname{Th} 17_{\text {high }}(\mathrm{n}=26), \mathrm{Th} 1_{\text {low }} \mathrm{Th} 17_{\text {low }}$ $(\mathrm{n}=56)$, and $\mathrm{Th} 1_{\text {high }} \mathrm{Th} 17_{\text {low }}(\mathrm{n}=5)$, which revealed distinct clinical characteristics. Patients with $T h 1_{\text {high }} T h 17_{\text {low }}$ profile had a significantly longer length of non-invasive ventilation time and length of hospital stay than patients with $\mathrm{Th} 1_{\text {high }}$ Th $17_{\text {high }}$ profile ( 7 vs 0 days, 22 vs 11 days, respectively, $p<0.05$ ), and had the highest AE frequency. Sputum levels of Th17 cytokines (IL-17A, IL-22, and IL-23) during AE were negatively correlated with AE frequency in the last 12 months $(r=-0.258,-0.289$ and -0.216 , respectively, $p<0.05)$. Moreover, decreased sputum IL-17A levels were independently associated with increased AE frequency, with an OR $(95 \% \mathrm{CI})$ of $0.975(0.958-0.993)$ and $p=0.006$.

Conclusion: Th1/Th17 imbalance during AE is associated with the severity of COPD. Decreased Th17 cytokine expression is correlated with increased AE frequency. The Th1/ Th17 balance may be a specific target for the therapeutic manipulation of COPD.

Keywords: chronic obstructive pulmonary disease, acute exacerbation, Th1 cytokines, Th17 cytokines, therapeutic

\section{Introduction}

Chronic obstructive pulmonary disease (COPD) is a major global health issue affecting approximately $10 \%$ of people over 40 years old. ${ }^{1}$ It is a chronic airway inflammatory disease characterized by persistent and poorly reversible airflow limitation.

Different T-helper (Th) cell cytokines have been identified in the pathogenesis of COPD. Th1 cytokines, such as interferon $\gamma$ (IFN- $\gamma$ ), tumor necrosis factor $\alpha$ (TNF- $\alpha$ ) and interleukin 2 (IL-2), are critical pro-inflammatory cytokines that activate
Correspondence: Zhancheng Gao;

Yali Zheng

Tel +86 I8810900430;

Tel +86 I50II45I5I5

Email zcgao@bjmu.edu.cn;

yali_zheng@|26.com
International Journal of Chronic Obstructive Pulmonary Disease 2020:15 1287-1299

1287

DovePress $f$ in $\boldsymbol{\nabla}$ 
macrophages, NK cells, and CD8+ T cells, leading to neutrophilic inflammation, promote pathogen clearance, and even lead to tissue destruction. ${ }^{2}$ Th2 cytokines (eg, IL-4, IL-5, IL-13, and IL-17E) are associated with immunity against extracellular parasites, allergy and airway hypersensitivity. ${ }^{2}$ Recent studies revealed that COPD patients with high a Th2 cytokine response had increased eosinophil counts, increased bronchodilator responsiveness and improved response to ICS treatment. ${ }^{3,4}$ IL-6, IL-1 $\beta$, IL-21, and IL-23 are essential for the differentiation, function and survival of Th17 cells, which produce mainly IL-17A, IL-21, IL-22, and IL-23. ${ }^{5}$ IL-17A and IL-22 induce epithelial cells to produce antimicrobial peptides, chemokines, and granulocyte growth factors to promote neutrophil accumulation in the airway. ${ }^{6} \mathrm{~T}$ regulatory cells (Treg) suppress the proliferation and cytokine production of other $T$ cells through the creation of anti-inflammatory cytokines, such as IL-10 and transforming growth factor- $\beta$ (TGF- $\beta){ }^{2}$ Several studies have shown an impaired balance between Treg cytokines and Th17 cytokines in COPD. ${ }^{7,8}$

Studies have shown that high levels of TNF- $\alpha$ and IL-17A are negatively correlated with pulmonary function in COPD.$^{9-11}$ However, therapies targeting these cytokines (infliximab and etanercept against TNF- $\alpha$ and CNTO 6785 against IL-17) have not shown promising effects in COPD patients, such as an improvement in pulmonary function and symptom scores or a decrease in exacerbations. ${ }^{12-16}$ Notably, an increase in infection and respiratory tract cancers was observed in these trials. Therefore, further studies are needed on the profiles of cytokines and the relationship between cytokines and clinical manifestations in COPD patients.

This study aimed to determine the airway Th cell cytokine profiles of AECOPD patients during hospitalization and a 120-day follow-up after discharge, and the relationships between cytokines and clinical features.

\section{Materials and Methods}

\section{Study Populations}

Patients diagnosed with acute exacerbations of COPD and hospitalized in Ningde City Hospital and Peking University People's Hospital from January 2017 to August 2017 were consecutively enrolled in the study (ClinicalTrials.gov ID, NCT03236480).

COPD was diagnosed according to the criteria of the Global Initiative for Chronic Obstructive Lung Disease (GOLD): ${ }^{17}$ (1) a history of exposure to cigarette smoke or other risk factors for the disease; (2) symptoms such as dyspnea, chronic cough and/or sputum production; and (3) a post-bronchodilator fixed ratio of forced expiratory volume in one second to forced vital capacity (FEV1/FVC) less than 0.70 . COPD severity was assessed using spirometry criteria outlined by the GOLD guidelines: ${ }^{17}$ 1) GOLD stage 1 , FEV1\% predicted is greater than or equal to $80 \% ; 2$ ) GOLD stage 2, FEV1\% predicted is greater than or equal to $50 \%$, but less than $80 \%$; 3) GOLD stage 3, FEV $1 \%$ predicted is greater than or equal to $30 \%$, but less than $50 \%$; and 4) GOLD stage 4, FEV1\% predicted is less than $30 \%$. An exacerbation of COPD was defined as an acute event characterized by a worsening of the patient's respiratory symptoms that were beyond normal day-to-day variations and led to a change in medication. ${ }^{17}$

The exclusion criteria were the presence of significant respiratory disease other than COPD, such as asthma, pulmonary tuberculosis, interstitial lung disease, or lung cancer, and the presence of chronic inflammatory disease, such as inflammatory bowel disease and connective tissue diseases.

For patients hospitalized before May 1st, 2017 (cohort A), clinical data during hospitalization were collected using a standard electronic medical record. For patients enrolled after May 1st 2017 (cohort B), additional follow-up for 120 days was requested. Follow-up forms, including smoking status, clinical symptom, and medication questions, were completed every 30 days. Before collecting any data, written informed consent was obtained from all patients. The Ethics Committee of Peking University People's Hospital approved the study (Approval number: 2016PHB202-01). This trial was conducted in accordance with the Declaration of Helsinki. The screening and follow-up process is shown in Figure 1.

\section{Sputum Sample Collection and Preservation}

Spontaneous sputum samples were collected in the first 24 hours after admission and 24 hours before discharge. In cohort B, sputum samples were also collected every 30 days during the 120-day follow-up. Sputum specimens were discharged into sterile cups. Qualified samples containing $<10$ epithelial cells and $>25$ leukocytes per low power field $(\times 100)$ were accepted for further processing and measurements. Samples were incubated with $1 \times$ volume $0.1 \%$ dithiothreitol (DTT) at $37^{\circ} \mathrm{C}$ for 30 minutes. After that, samples were mixed with an equal volume (to the DTT solution) of sterile normal saline, rocked for 5 minutes, and then centrifuged at $12,000 \mathrm{rpm}$ for 10 minutes at room temperature. ${ }^{18,19}$ The supernatants were stored at $-80{ }^{\circ} \mathrm{C}$ 


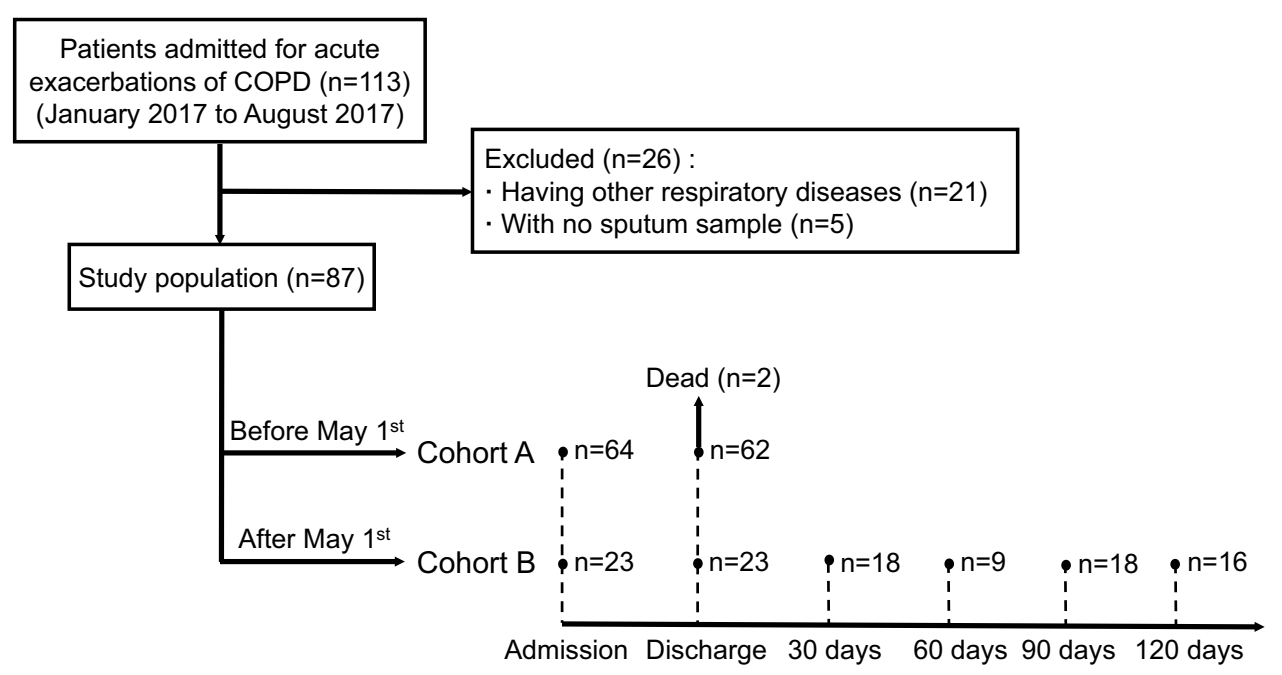

Figure I Flowchart of the study population.

Abbreviation: COPD, chronic obstructive pulmonary disease.

and transported in dry ice to the laboratory in Peking University People's Hospital.

\section{Cytokine Measurements}

Twelve cytokines, including Th1 (TNF- $\alpha$, IFN- $\gamma$, and IL-2), Th2 (IL-4, IL-5, and IL-17E), Th17 (IL-6, IL-17A, IL-21, IL-22, and IL-23) and Treg (IL-10) cytokines were measured using a Luminex Human Magnetic Assay Kit (LXSAHM12; R\&D Systems, Minneapolis, MN, USA) according to the manufacturer's instructions. Mean fluorescence intensity calculated from duplicates of each sample was collected using a Luminex 200 System (Luminex, Austin, TX, USA). The detection sensitivity was 1000 fluorochromes per microsphere. A seven-point standard curve including the blank, was used to calculate sample cytokine concentrations. The lower limit of detection (LOD) for each cytokine is $1.41 \mathrm{pg} /$ $\mathrm{mL}, 21.17 \mathrm{pg} / \mathrm{mL}, 29.89 \mathrm{pg} / \mathrm{mL}, 5.28 \mathrm{pg} / \mathrm{mL}, 1.38 \mathrm{pg} / \mathrm{mL}$, $92.78 \mathrm{pg} / \mathrm{mL}, 0.98 \mathrm{pg} / \mathrm{mL}, 2.79 \mathrm{pg} / \mathrm{mL}, 5.81 \mathrm{pg} / \mathrm{mL}, 6.96 \mathrm{pg} /$ $\mathrm{mL}, 30.09 \mathrm{pg} / \mathrm{mL}$ and $2.36 \mathrm{pg} / \mathrm{mL}$ for TNF- $\alpha$, INF- $\gamma$, IL-2, IL-4, IL-5, IL-17E, IL-6, IL-17A, IL-21, IL-22, IL-23, and IL-10, respectively.

\section{Statistical Analysis}

We restricted our analyses to cytokines for which $<30 \%$ of samples were below the lower LOD. ${ }^{20}$ The percentages of measurements below the lower LOD for the 12 cytokines were shown in Table S1. IL-2 levels at all 6-time points and IFN- $\gamma$, IL-21, and IL-10 levels at admission were excluded from further analysis. Then we imputed values below the lower LOD by a value of one-half of the lower LOD. ${ }^{21}$ After imputation, the normality of the imputed data was assessed using the Kolmogorov-Smirnov test. Subsequently, to evaluate whether the Th cell cytokines in sputum could be partitioned into clusters with distinct cytokine phenotypes, $k$-means partitional clustering ${ }^{22}$ was employed based on the cytokine levels of all subjects at admission. The elbow method $^{23}$ was used to determine the optimal $k$ number of clusters using the R package "NbClust"24 Spearman's rank correlation was performed to analyze the associations between cytokine levels and clinical parameters. Binary logistic regression was used to determine the risk factors affecting the frequency of acute exacerbations.

Generally, categorical variables are presented as numbers (percentages), parametric continuous variables are presented as the mean \pm standard deviation (SD), and nonparametric continuous variables are presented as median and interquartile ranges ( 25 th and 75 th percentiles). Continuous nonparametric data were analyzed using the Mann-Whitney U or Kruskal-Wallis test and continuous parametric data were analyzed using Student's $t$-test or one-way analysis of variance (ANOVA). All categorical data were analyzed using a chi-square or Fisher's exact test. All analyses were performed in SPSS Statistics (version 25.0; IBM, Chicago, IL, USA). A two-sided $p$-value $<0.05$ was considered statistically significant; confidence intervals (CIs) were set at 95\%.

\section{Results}

\section{Population Characteristics}

A total of eighty-seven patients (82 men and five women) were included in the study, 64 in cohort A and 23 in cohort B, 
with a mean age of $72 \pm 8.5$ years. Individually, 13, 32, and 42 patients were classified as GOLD stages 1 2, 3, and 4, respectively. A total of 16 patients (18.4\%) received assisted ventilation during hospitalization, and two died (2.3\%). As shown in Table 1, there were no significant differences in age, sex, smoking history, or the prevalence of comorbidities and complications among patients at different GOLD stages, except for the incidence of non-invasive ventilation, which was significantly higher in patients at GOLD stage 4 .

\section{Sputum Levels of T Helper Cell Cytokines During Hospitalization}

To understand changes in Th cell cytokines during COPD exacerbations, we compared the levels of cytokines at admission and discharge. As shown in Figure 2, the levels of Th1 (TNF- $\alpha$ ), Th2 (IL-17E), and Th17 (IL-17A and IL-22) cell cytokines at admission were significantly higher than those at discharge, and IL-22 and TNF- $\alpha$ exhibited the most significant changes with 2.8 -fold and 2.0-fold increases, respectively. IL-10 content was low both during AEs and at the 120-day followup, indicating a defective IL-10 response in COPD patients, as previously reported. ${ }^{11}$ No significant differences in sputum levels of cytokines were observed among different GOLD stages. Likewise, no significant differences were observed in clinical classifications based on age, sex, or disease complications such as respiratory failure, cor pulmonale, etc (all $p>0.05$, data not shown).

\section{Cluster Analysis Revealed Three Distinct Th Cell Cytokine Profiles}

To evaluate whether sputum samples from all subjects at admission could be partitioned into clusters with distinct Th cell cytokine profiles, we utilized a $k$-means clustering algorithm. This approach yielded three separate cytokine clusters (as shown in Figure 3A), with 26, 56, and five patients in cluster 1, cluster 2, and cluster 3, respectively.

The Kruskal-Wallis test revealed that 7 out of 8 cytokines were significantly different among the clusters (all $p<0.01$, as shown in Table S2). We further performed pairwise comparisons. As shown in Figure 4, Th1 (TNFa), Th2 (IL-17E), and Th17 (IL-6, IL-17A, and IL-22) cell cytokine expression significantly differed from each other. In cluster 3, the highest levels of TNF- $\alpha$ and IL-6 ( $\sim 25.9$-fold and $\sim 107.7$-fold compared to those in the lowest cluster, respectively) and the lowest level of IL-17A
( $\sim 0.2$-fold compared to that in the highest cluster) were observed. Meanwhile, the highest levels of IL-17A, IL-22, and IL-17E (approximately 4.3-fold, 2.7-fold, and 3.5-fold compared to those in the lowest cluster, respectively) were observed in cluster 1 . Notably, the levels of IL-6, a cytokine that promotes Th17 cell differentiation, were highest in cluster $3(p<0.001)$, while the primary effector cytokines of Th17 cells, IL-17A and IL-22, were the lowest $(p<0.001)$. The data indicated IL-17A and IL-22 deficiencies in the COPD patients of cluster 3. In general, we identified three distinct Th cell cytokine profiles through cluster analysis, which were termed "Th1 $1_{\text {high }} \mathrm{Th} 17_{\text {high" }}$ " (clus-

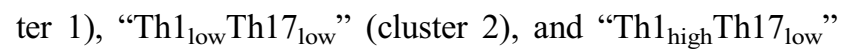
(cluster 3).

We assumed that differential cytokine expression is associated with different clinical characteristics. We compared the clinical data among these three clusters (Table 2 and Figure 3B-D). As shown in Table 2, the overall distributions of GOLD stages in distinct clusters were similar to each other. However, patients in cluster 3 ("Th1 $1_{\text {high }} T h 17_{\text {low") }}$ suffered from the most extended length of hospital stay and the longest length of non-invasive ventilation (Kruskal-Wallis test, $p=0.019$ and $p=0.011$, respectively). Moreover, they had the lowest body mass index (BMI) and the highest AE frequency (Kruskal-Wallis test, $p=0.002$, and $p=0.035$, respectively).

Spearman correlation analysis between clinical manifestations and cytokines revealed that $\mathrm{AE}$ frequency was negatively correlated with sputum levels of Th17 cytokines (IL-17A, IL-22, and IL-23) and Th2 cytokines (IL-17E) (all $p<0.05$ ), as shown in Figure 5. In addition, the level of IL-6 was positively correlated with the length of non-invasive ventilation $(r=0.254, p<0.05)$.

\section{ThI7 Cytokine Expression Levels Were Related to AE Frequency in COPD Patients}

We further analyzed the correlations between sputum levels of cytokines and AE frequency. As shown in Table 3, in patients with high AE frequency (more than two times in the previous 12 months), the levels of IL-17A and IL-22 were significantly lower than those in patients with a relatively low $\mathrm{AE}$ frequency ( $\leq 2$ times in the previous 12 months) ( $p=0.036$ and 0.019 ). Table 3 also lists other variables that exhibited significant differences between patients with a high $\mathrm{AE}$ frequency and those with a low AE frequency, including the incidence of chronic cor pulmonale, GOLD 
Table I Clinical Characteristics of the Patients According to GOLD Stages

\begin{tabular}{|c|c|c|c|c|}
\hline & $\begin{array}{l}\text { GOLD } \\
\text { Stage I, } 2 \\
(n=13)\end{array}$ & $\begin{array}{l}\text { GOLD } \\
\text { Stage } 3 \\
(n=32)\end{array}$ & $\begin{array}{l}\text { GOLD } \\
\text { Stage } 4 \\
(n=42)\end{array}$ & $p$-value \\
\hline Age, yrs & $74.08 \pm 6.291$ & $73.22 \pm 9.882$ & $70.40 \pm 7.908$ & 0.239 \\
\hline Male & $12(92.3 \%)$ & $29(90.6 \%)$ & $4 \mathrm{l}(97.6 \%)$ & 0.354 \\
\hline BMI, $\mathrm{kg} / \mathrm{m}^{2}$ & $21.17 \pm 2.43$ & $20.93 \pm 2.69$ & $22.00 \pm 3.16$ & 0.281 \\
\hline Pack-years & $27.88 \pm 21.60$ & $27.72 \pm 24.89$ & $36.26 \pm 25.91$ & 0.289 \\
\hline Current smokers & $7(53.8 \%)$ & 14 (43.8\%) & $12(28.6 \%)$ & 0.181 \\
\hline \multicolumn{5}{|l|}{ Comorbidities } \\
\hline Diabetes mellitus & I (7.7\%) & $4(12.5 \%)$ & 7 (16.7\%) & 0.764 \\
\hline Hyperlipidemia & $0(0.0 \%)$ & $0(0.0 \%)$ & $3(7.1 \%)$ & 0.379 \\
\hline Coronary heart disease & $5(38.5 \%)$ & $6(18.8 \%)$ & $13(31.0 \%)$ & 0.323 \\
\hline Chronic kidney disease & $0(0.0 \%)$ & $2(6.3 \%)$ & $0(0.0 \%)$ & 0.265 \\
\hline Acute exacerbation frequency in previous 12 months & $2(I-4)$ & $2(I-5)$ & $3(2.75-6.25)$ & 0.094 \\
\hline COPD medications & II (84.6\%) & $24(75.0 \%)$ & 40 (95.2\%) & 0.042 \\
\hline $\mathrm{ICS}+\mathrm{LABA}$ & II (84.6\%) & $21(65.6 \%)$ & $33(78.6 \%)$ & 0.517 \\
\hline LAMA only & $0(0.0 \%)$ & $0(0.0 \%)$ & I (2.4\%) & 0.274 \\
\hline LABA + LAMA & $0(0.0 \%)$ & I (3.1\%) & $0(0.0 \%)$ & 0.517 \\
\hline ICS + LABA + LAMA & $0(0.0 \%)$ & $2(25.0 \%)$ & $6(14.3 \%)$ & 0.246 \\
\hline Duration, yrs & $2(2-4)$ & $2(2-3)$ & $3(2-4)$ & 0.607 \\
\hline \multicolumn{5}{|l|}{ Outcome } \\
\hline Type I respiratory failure & $3(23.1 \%)$ & 7 (21.9\%) & $6(14.3 \%)$ & 0.631 \\
\hline Type II respiratory failure & $3(23.1 \%)$ & $9(28.1 \%)$ & II (26.2\%) & 0.940 \\
\hline Non-invasive ventilation & $0(0.0 \%)$ & $2(6.3 \%)$ & $13(3 \mid \%)$ & 0.004 \\
\hline Tracheal intubation & $0(0.0 \%)$ & $0(0.0 \%)$ & $2(4.8 \%)$ & 0.641 \\
\hline In-hospital mortality & $0(0.0 \%)$ & $0(0.0 \%)$ & $2(4.8 \%)$ & 0.641 \\
\hline Length of hospital stay, days & $13(9-20)$ & II (10-15) & $13(11-16)$ & 0.367 \\
\hline
\end{tabular}

Abbreviations: GOLD, Global Initiative for Chronic Obstructive Lung Disease; BMI, body mass index; ICS, inhaled corticosteroids; LABA, long-acting $\beta_{2}$-agonists; LAMA, long-acting muscarinic antagonist.

stage, modified British Medical Research Council (mMRC) scores, 6-minute walking test results, COPD assessment test (CAT) scores and the levels of IL-23, and we also included the levels of IL-17E which were correlated with AE frequency. We further performed backward stepwise logistic regression to analyze the independent relationship between Th17 cytokines (IL-17A and IL-22) and high AE frequency. As shown in Table 3, increased sputum levels of IL-17A were independently related to a lower risk of $\mathrm{AE}$, with an OR $(95 \% \mathrm{CI})$ of $0.975(0.958-0.993)$ and a $p=0.006$.

\section{Levels of IL-I7A and IL-22 Over the I20-Day Follow-Up}

We assumed that reduced expression levels of IL-17A and IL-22 indicated higher frequencies of AE. Values of fourtime points during the 120-day follow up were further assessed. As shown in Figure 6, patients who revealed lower levels of IL-22 and IL-17A suffered a higher incidence of $\mathrm{AE}$ in the next 30 days, although without statistical significance $(p>0.05)$. The tendency remained the same for IL-22 at all four-time points of follow-up, while IL-17A only maintained the trend 90 days after discharge.

\section{Discussion}

In the present study, we characterized the Th cell cytokine profiles, including those for Th1, Th2, and Th17 cells and Treg, in sputum samples of 87 COPD patients during acute exacerbations. We identified three distinct Th cell cytokine profiles during $\mathrm{AE}$, including $\mathrm{Th} 1_{\text {high }} \mathrm{Th} 17_{\text {high }}$, Th1 $1_{\text {low }}$ Th1 $17_{\text {low }}$, and Th1 $1_{\text {high }}$ Th1 $17_{\text {low }}$ profiles, which exhibited significantly different clinical outcomes. The Th1 $1_{\text {high }} T h 17_{\text {low }}$ profile during $\mathrm{AE}$ was associated with increased duration of NPPV, lengths of hospital stay, and AE frequency. Moreover, decreased sputum IL-17A levels were independently associated with increased $\mathrm{AE}$ frequency to more than twice per year. We also identified that defective IL-22 


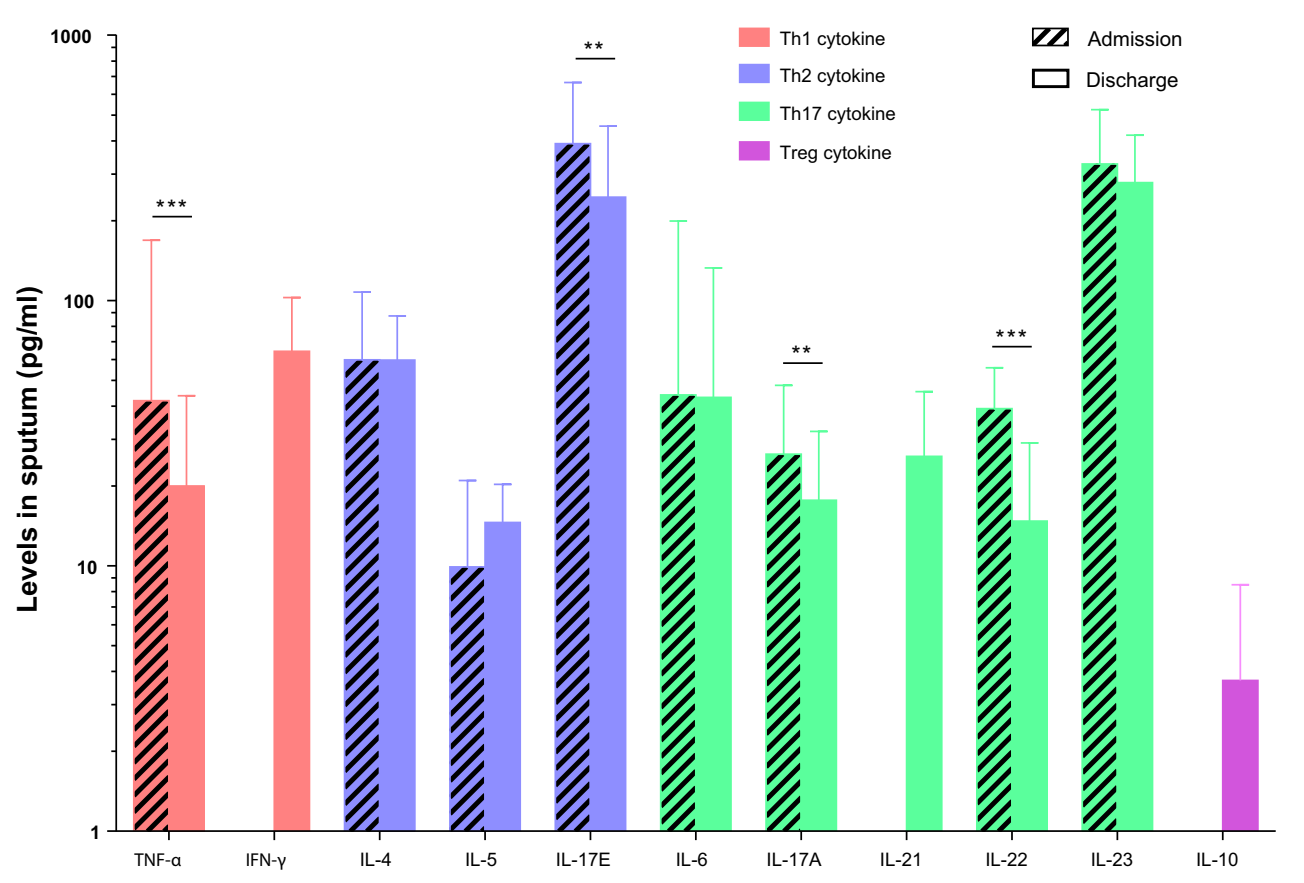

Figure 2 Levels of cytokines at admission and discharge. $* * p<0.01$, ${ }^{* * *} p<0.001$. Abbreviations: TNF, tumor necrosis factor; IFN, interferon; IL, interleukin.

expression in COPD might persist and indicate acute exacerbations in the short term.

Consistent with previous studies, our study showed that high expression of Th1 cytokines during exacerbations was related to poor prognosis, which might be due to the role of Th1 cytokines in promoting inflammatory responses, mucus secretion, and tissue destruction. We found that the levels of TNF- $\alpha$ exhibited the most significant change during exacerbation among Th1 cytokines. As an essential proinflammatory cytokine, TNF- $\alpha$ plays a critical role in the stable stage and during AE of COPD. An animal study showed that TNF- $\alpha$ was associated with cigarette-induced airway macrophage and neutrophil influx, production of matrix metalloproteinase (MMP), and the development of emphysema. ${ }^{25}$ There is an increase in the levels of TNF- $\alpha$ in both induced sputum and serum in patients with stable COPD, with a further rise during exacerbations. ${ }^{10,26}$ Singh et $\mathrm{al}^{10}$ found that elevated serum levels of TNF- $\alpha$ in patients with stable COPD were related to reduced predicted FEV1\%. The evidence above indicates that TNF- $\alpha$ is closely correlated with disease progression and prognosis in COPD patients. Patients in cluster 3 had the highest levels of TNF- $\alpha$ and lowest pulmonary function parameters (FVC/FEV1 and FEV1\%pred, without significant difference, however), which is consistent with the evidence above. They also had the lowest BMI among the 3 clusters. Previous studies suggest that TNF- $\alpha$ would induce loss of skeletal muscle mass in multiple ways, ${ }^{27,28}$ and was associated with the increased secretion of some adipokines (eg leptin and adiponectin), which were also related to low body weight in COPD patients. ${ }^{29,30}$ In addition, with the significant decline of ventilator function, these patients persistently made excess respiratory exercise than others, which also contributed to the severe weight-loss.

Another pro-inflammatory cytokine, IL-6, was related to the poor prognosis of COPD patients in our study. IL-6 is a recognized biomarker of inflammation. Hurst et $\mathrm{al}^{31}$ found that levels of IL- 6 in the serum and airway during exacerbation were correlated with other inflammatory markers, such as leukocyte count, myeloperoxidase (MPO) and c-reactive protein (CRP). Pinto-Plata et $\mathrm{al}^{32}$ reported that the levels of IL-6 were significantly correlated with changes in dyspnea and FEV1 in patients hospitalized for exacerbation of COPD. Our results are consistent with the above studies, implying that severe inflammatory response during exacerbation leads to a poor clinical outcome.

IL-17A, IL-17F, and IL-22 are the key components of Th17 cytokines, produced by Th17 lymphocytes, and many innate immune cells, such as neutrophils, eosinophils, basophils, mast cells, $\gamma \delta \mathrm{T}$-cells, type 3 innate lymphoid cells (ILC3), natural killer (NK) cells. ${ }^{5,33}$ In the lung, IL-17A binds to its receptor, IL17RA-IL-17RC, expressed on many kinds of cells such as epithelial and vascular endothelial cells, 


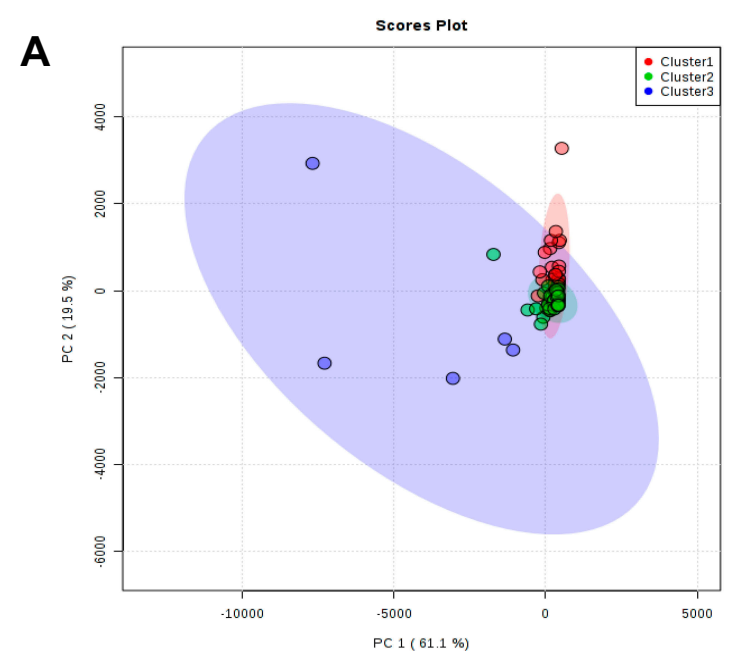

B

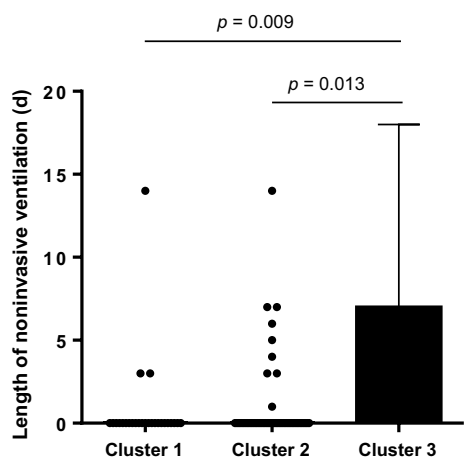

C

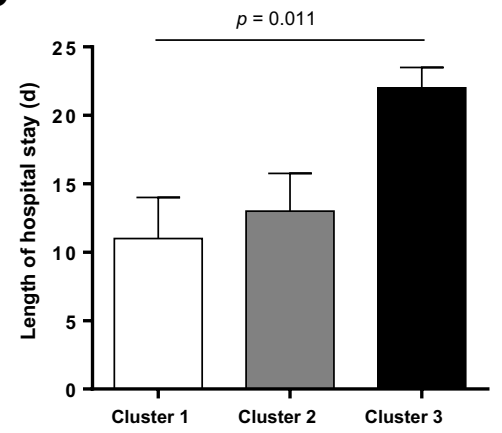

D

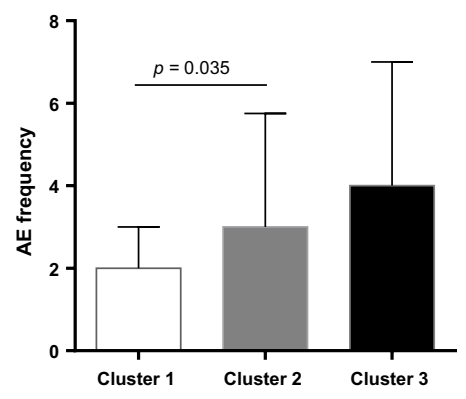

Figure 3 Grouping using k-means clustering $(\mathbf{A})$ and clinical features across the three clusters (B-D). According to the levels of cytokines at admission, 87 patients were divided into three clusters (cluster I, cluster 2 and cluster 3, painted in red, green and blue, respectively, in the figure) using a $k$-means clustering algorithm.

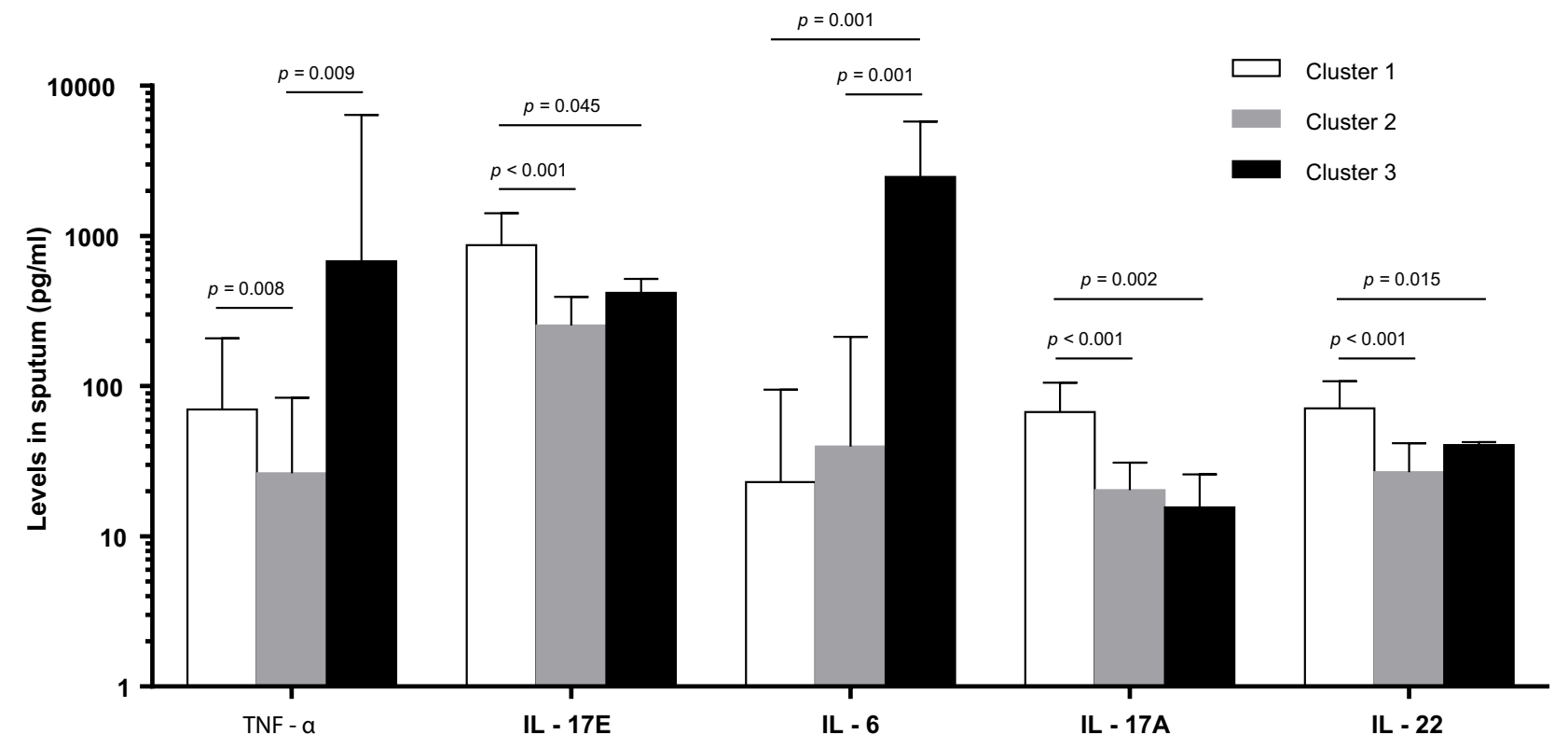

Figure 4 Levels of cytokines at admission across the three clusters. Abbreviations: TNF, tumor necrosis factor; IL, interleukin. 
Table 2 Clinical Characteristics of the Patients in Three Clusters

\begin{tabular}{|c|c|c|c|c|}
\hline & $\begin{array}{l}\text { Cluster I } \\
(n=26)\end{array}$ & $\begin{array}{l}\text { Cluster } 2 \\
(n=56)\end{array}$ & $\begin{array}{l}\text { Cluster } 3 \\
(n=5)\end{array}$ & $p$-value \\
\hline Age, yrs & $71.54 \pm 8.941$ & $72.38 \pm 8.616$ & $70.00 \pm 6.364$ & 0.799 \\
\hline Male & $24(92.3 \%)$ & $54(96.4 \%)$ & $4(80.0 \%)$ & 0.188 \\
\hline BMl, kg/m² & $20.67 \pm 3.49$ & $22.13 \pm 2.21$ & $|7.5| \pm 3.59$ & 0.002 \\
\hline Smoking history & $20(76.9 \%)$ & 47 (83.9\%) & $3(60 \%)$ & 0.293 \\
\hline Pack-years & $27.17 \pm 24.39$ & $34.04 \pm 23.95$ & $32.00 \pm 40.87$ & 0.518 \\
\hline Current smokers & $10(38.5 \%)$ & $23(41.1 \%)$ & $0(0.0 \%)$ & 0.237 \\
\hline \multicolumn{5}{|l|}{ Comorbidities } \\
\hline Diabetes mellitus & $2(7.7 \%)$ & $10(17.9 \%)$ & $0(0.0 \%)$ & 0.412 \\
\hline Hyperlipidemia & $0(0.0 \%)$ & $3(5.4 \%)$ & $0(0.0 \%)$ & 0.622 \\
\hline Coronary heart disease & 9 (34.6\%) & $13(23.2 \%)$ & $2(40.0 \%)$ & 0.402 \\
\hline Chronic kidney disease & $2(7.7 \%)$ & $0(0.0 \%)$ & $0(0.0 \%)$ & 0.199 \\
\hline FEVI/FVC, \% & $51.4 \pm 9.9^{\mathrm{a}}$ & $47.9 \pm 9.5^{\mathrm{b}}$ & $45.0 \pm 14.7$ & $0.27 \mid$ \\
\hline FEVI, \% predicted & $32.8(25.3-45.7)^{\mathrm{a}}$ & $29.5(\mid 8.1-45.1)^{\mathrm{b}}$ & $27.4(19.2-47.2)$ & 0.230 \\
\hline \multicolumn{5}{|l|}{ GOLD } \\
\hline 1 and 2 & $4(15.4 \%)$ & $8(14.3 \%)$ & I (20.0\%) & 0.889 \\
\hline 3 & 9 (34.6\%) & 22 (39.3\%) & I (20.0\%) & 0.810 \\
\hline 4 & $13(50.0 \%)$ & $26(46.4 \%)$ & $3(60.0 \%)$ & 0.823 \\
\hline Acute exacerbation frequency in previous 12 months & $2(1-3)$ & $3(2-5.75)$ & $4(I-7)$ & 0.040 \\
\hline \multicolumn{5}{|l|}{ Outcome } \\
\hline Type I respiratory failure & $3(15.4 \%)$ & $12(21.4 \%)$ & $0(0.0 \%)$ & 0.651 \\
\hline Type II respiratory failure & $7(26.9 \%)$ & $15(26.8 \%)$ & I (20.0\%) & 1.000 \\
\hline Non-invasive ventilation & $3(11.5 \%)$ & $9(16.1 \%)$ & $3(60.0 \%)$ & 0.050 \\
\hline Length of non-invasive ventilation, days & $0(0-0)$ & $0(0-0)$ & $7(0-18)$ & 0.011 \\
\hline Tracheal intubation & I (3.8\%) & $0(0.0 \%)$ & I (20.0\%) & 0.037 \\
\hline In-hospital mortality & I (3.8\%) & $0(0.0 \%)$ & I (20.0\%) & 0.037 \\
\hline Length of hospital stay, days & II (9-14.25) & $13(||-\mid 5.75)$ & $22(15-23.5)$ & 0.019 \\
\hline
\end{tabular}

Notes: Pulmonary function parameters (FEVI/FVC and FEVI) are values after the use of a bronchodilator at acute stage. ${ }^{a} n=22 ;{ }^{b} n=5 I$.

Abbreviations: GOLD, Global Initiative for Chronic Obstructive Lung Disease; BMI, body mass index; FVC, forced vital capacity; FEVI, forced expiratory volume in one second; TNF, tumor necrosis factor; IL, interleukin.

fibroblasts, neutrophils, macrophages, dendritic cells (DCs), and eosinophils, and induces the production of proinflammatory cytokines (eg, IL- 6 and TNF- $\alpha$ ) and chemokines (eg, CXCL8, CXCL1, CXCL5, G-CSF, and GM-CSF), promoting the granulopoiesis and recruitment of macrophages and neutrophils. ${ }^{33,34}$ Moreover, both of IL-17A and IL-22 participate in the induction of antimicrobial peptides (such as defensins) in a synergistic way. ${ }^{5}$ Sharing high homology with IL-17A, IL-17F has similar function but is less active. ${ }^{35}$ IL-22 binds to its receptor, IL-22R1-IL-10R2, expressed on cells with epithelial origin, and is signalled primarily through STAT3 pathway. ${ }^{36}$ In airway, IL-22 helps to maintain and restore the integrity of epithelial barrier, and stimulates the production of protective mucus from goblet cells. ${ }^{36} \mathrm{IL}-22$ also induces the expression of proteins involved in anti-apoptosis, cell cycle and proliferation, thus contributing to epithelial cell proliferation and survival. ${ }^{36} \mathrm{IL}-21$, secreted primarily by Th17 cells and IL-23, secreted primarily by DCs, sustain and promote the production of Th17 cytokines. $^{34}$

We determined Th17 cytokine levels in COPD patients during and after exacerbation and found that IL-17A and IL-22 contents increased significantly during an exacerbation, which was consistent with results from other studies. ${ }^{37,38}$ Furthermore, we found that COPD severity was correlated with Th17 cytokine levels in sputum during exacerbation and those who cannot produce sufficient IL-17A and IL-22 suffer from a severe course, implying that Th17 cytokines play a protective role during exacerbation. This finding seems to be contradictory with previous studies, in which Th17 cytokines play a harmful role in the pathogenesis and progression of COPD, such as being involved in neutrophilic inflammation in the lung, ${ }^{38}$ alveolar cell apoptosis, ${ }^{39}$ airway fibrosis, ${ }^{40}$ 

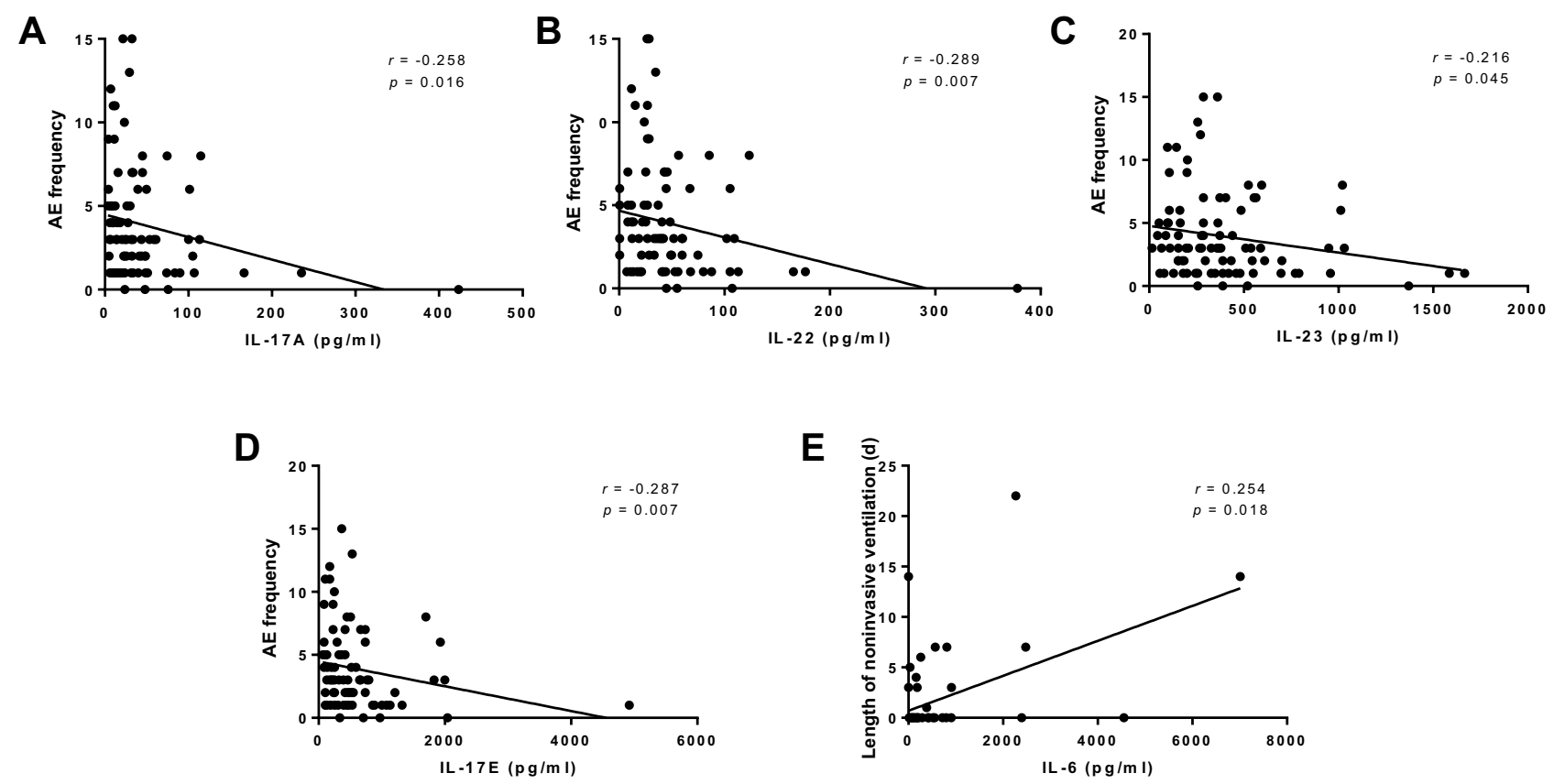

Figure 5 Spearman correlation analysis between clinical features and the levels of cytokines at admission. $r$ is the correlation coefficient. Levels of IL-I7A, IL-22, IL-23, and IL-I7E in sputum on admission are positively correlated with AE frequency in the last I 2 months (A-D). Levels of IL-6 in sputum on admission is positively correlated with length of non-invasive ventilation (E).

Abbreviations: $\mathrm{AE}$, acute exacerbation; IL, interleukin.

emphysema development ${ }^{41}$ and pulmonary function decline. ${ }^{9,11,37}$ Most exacerbations of COPD are caused by infection. Nontypeable Haemophilus influenzae (NTHi) and Streptococcus pneumonia (S. pneumonia) are the most common bacteria associated with COPD exacerbation. ${ }^{42}$ It has been confirmed in animal models and human immune cells that Th17 cells and cytokines are activated and participate in host defense and clearance of pathogens during infection with NTHi and S. pneumonia. ${ }^{43-46}$ Therefore, our results suggest that Th17 cytokine levels increase during exacerbation and participate in the host defense against pathogens, and patients with low levels of Th17 cytokines have a prolonged course and increased severity of disease conditions.

The correlation between Th17 cytokines and AE frequency in COPD patients has not been investigated in previous studies. Our findings showed that a high AE frequency is correlated with decreased sputum Th17 cytokine levels during exacerbation. Although the correlation index was relatively low $(\mathrm{r}<0.3)$, which may due to the relatively small size. But the logistic regression verified that a relative low level of IL-17A is an independent risk factor for frequent AE. We infer that the anti-infection function of Th17 cytokines can reduce the risk of infection in patients with COPD, thereby reducing AE frequency. This hypothesis is supported by clinical data from patients with psoriasis who were treated with secukinumab, an anti-IL-17A antibody, who showed an elevated rate of infection, especially respiratory disease. ${ }^{47}$ Furthermore, an increased rate of exacerbation was observed in another clinical trial in which patients with COPD were treated with CNTO 6785, another anti-IL-17 antibody. ${ }^{16}$ These results imply that the role of Th17 cytokines in COPD is quite complicated. Although the Th17 cytokine response is related to chronic pulmonary inflammation and airway remodelling in COPD patients, it is vital to resist pathogens and prevent infection and frequent exacerbation. Previous studies that found that Th17 cytokines promoted disease progression were based mostly on results in the stable stage. Our studies showed that decreased levels of IL-17A and IL-22 during exacerbations were related to course severity and $\mathrm{AE}$ frequency. This result implies that Th17 cytokines might play different roles in the stable stage and exacerbation stage, and subsequent studies need to pay attention to this difference.

Our study showed that patients with $\mathrm{Th} 1_{\text {high }} \mathrm{Th} 17_{\text {low }}$ profiles had a worse prognosis than those with $\mathrm{Th} 1_{\text {high }}$ Th17 high patterns. This result suggests that among patients who had high levels of Th1 cytokines, those who could produce sufficient Th17 cytokines would have better clinical outcomes than those who could not. In other words, patients with a Th1/Th17 imbalance have the worst clinical manifestations. We hypothesize that the Th1/Th17 
Table 3 Univariate Analysis and Multivariate Regression to Identify Independent Factors That Correlated with High AE Frequency

\begin{tabular}{|l|l|l|l|l|}
\hline \multirow{2}{*}{ Variable } & \multicolumn{2}{|l|}{ Univariate Analysis } & \multicolumn{2}{l|}{ Multivariate Logistic Regression } \\
\cline { 2 - 5 } & $\boldsymbol{P}$ & OR (95\% Cl) & $\boldsymbol{P}$ & OR (95\% CI) \\
\hline Age, yrs & 0.084 & $1.047(0.993-1.104)$ & & \\
Male & 0.991 & $1.010(0.160-6.379)$ & & \\
Chronic cor pulmonale & 0.005 & $5.647(1.517-21.016)$ & & \\
GOLD 4 & 0.003 & $4.000(1.591-10.056)$ & & $12.965(3.293-51.049)$ \\
mMRC score $>2$ & $<0.001$ & $5.500(2.143-14.118)$ & & $0.975(0.958-0.993)$ \\
6MWD $<250 m$ & 0.001 & $4.705(1.858-11.912)$ & & \\
CAT score $>20$ & $<0.001$ & $8.140(2.859-23.178)$ & & \\
IL-I7A, pg/mL & 0.036 & $0.986(0.973-0.999)$ & 0.006 & \\
IL-22, pg/mL & 0.019 & $0.984(0.970-0.997)$ & & \\
IL-23, pg/mL & 0.039 & $0.998(0.997-1.000)$ & & \\
IL-I7E, pg/mL & 0.114 & $0.999(0.998-1.000)$ & & \\
\hline
\end{tabular}

Abbreviations: GOLD, Global Initiative for Chronic Obstructive Lung Disease; mMRC, modified British Medical Research Council; 6MWD, 6-minute walking distance; CAT, COPD assessment test; IL, interleukin.

imbalance is due mainly to some COPD patients having an impaired ability to produce a Th17 response (especially IL-17A and IL-22 production), which results in increased susceptibility to infection, thereby leading to increased exacerbation severity and frequency. Andelid et $\mathrm{al}^{48}$ found that IL-17 levels in the blood were markedly lower in stable COPD patients than in non-smoker control subjects, and the reduction was more significant in patients with severe disease. They also reported that lower IL-17 levels were related to opportunistic pathogen colonization in COPD patients. The group of Barczyk et $\mathrm{al}^{49}$ reported lower levels of IL-17 in the sputum of COPD patients than in that of chronic bronchitis patients. Also, patients with AECOPD were found to had lower IL-17A levels in both blood and sputum than healthy controls and patients with severe exacerbations had lower than those with mild exacerbations. $^{50}$ These findings suggest that the Th17 pathway could be impaired in COPD patients. Pichavant et $\mathrm{al}^{44}$ found an increase in IL-17 and IL-22 levels in BAL and lung lysates of air-exposed mice but not in those of CS (cigarette smoke) -exposed mice after S. pneumonia challenge, and they found the same defect in PBMCs from COPD patients. Furthermore, in that study, they found reduced levels of IL-17-producing NK and NKT cells and IL-22-producing conventional T cells, NK cells, NKTlike cells, and Lin-negative cells in CS-exposed mice. ${ }^{44}$ Several studies suggest that chronic CS exposure affects the function of DCs (such as maturation, migration, and endocytosis), resulting in reduced secretion of pro-Th17 cytokines such as IL-1 $\beta$ and IL-23, then reduced activation of Th17 response. ${ }^{44,45,51,52}$ We found levels of IL-23 was negatively correlated to AE frequency, which may conform to the defect of DCs function.

Some studies suggest the difference of Th17 response in COPD patients with different exposure history. In COPD related to cigarette smoke exposure, higher frequency of CD4+ Th17 cells and level of IL-17A in peripheral blood was described comparing with COPD with biomass-burning exposure. ${ }^{53,54}$ However, we found no distinct difference of distribution of smokers and non-smokers among three clusters in our study (as shown in Table 2), no difference of cytokine levels between patients with and without smoking history, either (as shown in Table S3). Moreover, some researchers showed the altered IL-17A production related to functional single nucleotide polymorphism (SNP) in promotor of IL-17A gene. For example, rs8193036 $\mathrm{T}>\mathrm{C}$ downregulates, and rs2275913 G > A upregulates the secretion of IL-17A through influencing transcription factor binding activity. ${ }^{55,56}$ PonceGallegos et $\mathrm{al}^{54}$ showed that COPD patients carrying rs8193036 CC genotype had lower IL-17A levels than those who carry TT and TC genotypes. Therefore, many factors combined result in the different ability to produce Th17 response in COPD patients, which may be one of the reasons for poor clinical trial results, and further clinical trials should take this fact into account to select patients who may benefit from anti-Th17 cytokine treatment.

The limitation of our study is that we did not determine the cytokine profiles in the sputum of healthy people, and the difference in Th17 cytokine levels between COPD patients and healthy people could not be clarified. And we did not determine sputum cellular profiles or identify different types of inflammatory cells in sputum samples. Our follow-up data 


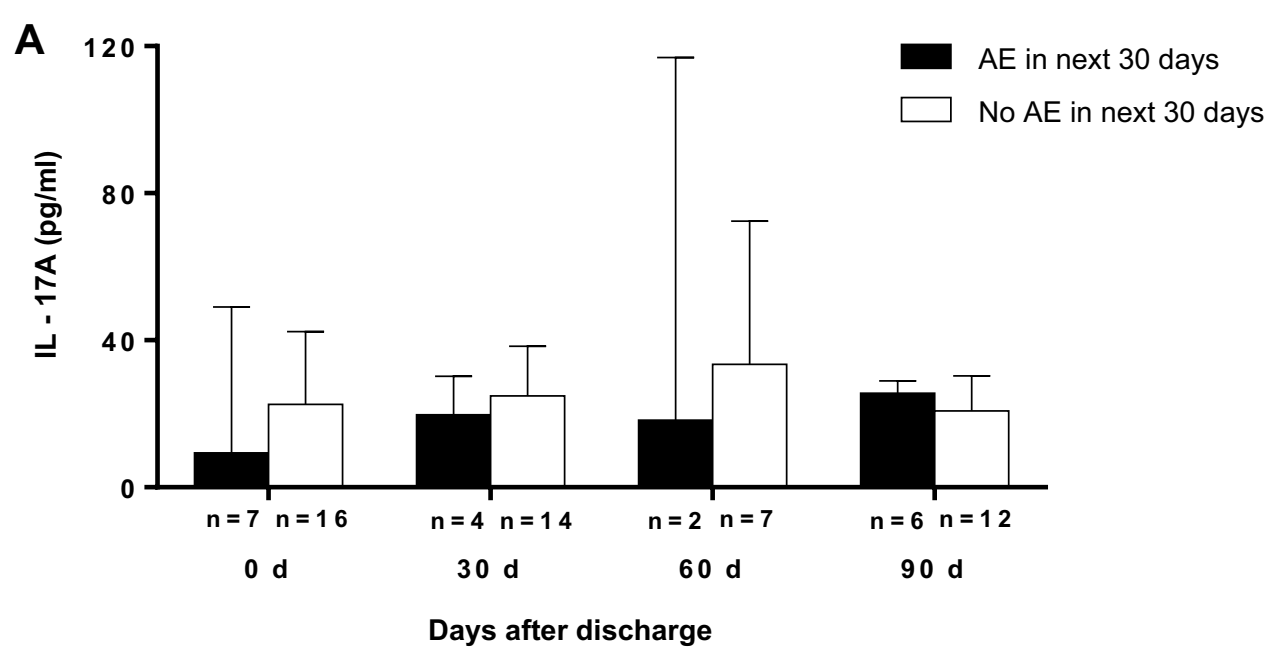

B

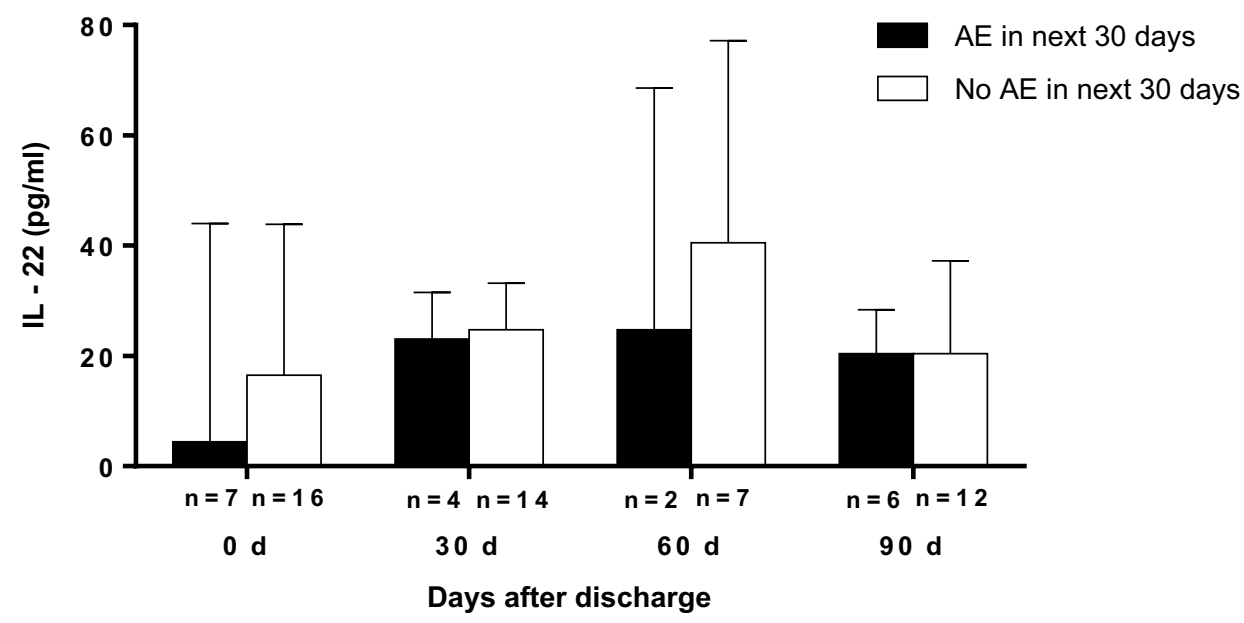

Figure 6 Levels of ThI7 cytokines during the 120-day follow-up. Patients with lower levels of IL-I7A (A) and IL-22 (B) tended to have a higher risk of AE in the next 30 days, although without statistical significance $(p>0.05)$.

showed a trend in which Th17 cytokine levels change after discharge, and further studies with more follow-up cases and longer time course are needed to verify this result.

\section{Conclusions}

Our study determined the cytokine profiles in the sputum of patients with COPD. We identified three distinct Th cell cytokine profiles during AE, namely $T h 1_{\text {high }} T h 17_{\text {high }}, T h 1_{\text {low }}$ Th1 $7_{\text {low, }}$ and Th1 $1_{\text {high }}$ Th $17_{\text {low }}$ patterns, which exhibited significantly different clinical outcomes. Th1/Th17 imbalance during $\mathrm{AE}$ is associated with the severity of COPD. Sufficient Th17 cytokine responses (production of IL-17A and IL-22, especially IL-17A) can reduce the frequency and severity of the exacerbation. The Th1/Th17 balance may be a specific target for therapeutic manipulation of COPD.

\section{Abbreviations}

6MWD, 6-minute walking distance; AE, acute exacerbation; BMI, body mass index; CAT, COPD assessment test; COPD, chronic obstructive pulmonary diseases; CRP, c-reactive protein; DTT, dithiothreitol; FEV1, forced expiratory volume in one second; FVC, forced vital capacity; GOLD, Global Initiative for Chronic Obstructive Lung Disease; IFN, interferon; IL, interleukin; LOD, limit of detection; mMRC, modified British Medical Research Council; MMP, matrix metalloproteinase; MPO, myeloperoxidase; NTHi, Nontypeable Haemophilus influenza; S. pneumonia, Streptococcus pneumonia; TGF, transforming growth factor; Th, T-helper; TNF, tumor necrosis factor; Treg, T regulatory cells. 


\section{Data Sharing}

The datasets used during the current study, including clinical data and cytokine levels of participants are available from the corresponding author on reasonable request, and we will make a reply as soon as possible.

\section{Acknowledgments}

The study was funded by the National Key Research and Development Program of China (2016YFC0903800), the National Science and Technology Major Project of China (2017ZX10103004-006), the Medical Technology Promotion Research Project of Ningde City, Fujian Province (2109901) and the Research project for Young Scientists of Fujian Provincial Health Commission (2017-2-95).

\section{Author Contributions}

All authors contributed toward data collection, statistical analysis, drafting and critically revising the paper, gave final approval of the version to be published, and agree to be accountable for all aspects of the work.

\section{Disclosure}

The authors report no conflicts of interest in this work.

\section{References}

1. Barnes PJ, Burney PG, Silverman EK, et al. Chronic obstructive pulmonary disease. Nat Rev Dis Primers. 2015;1(1):15076. doi:10.1038/nrdp.2015.76

2. Shannon AC, Matthew JR, Gary AK. T-cell immunity. In: Ronald H, Edward JB, Leslie ES, et al. editors. Hematology: Basic Principles and Practice. Philadelphia: Elsevier; 2018:221-239.

3. Christenson SA, Steiling K, van den Berge M, et al. AsthmaCOPD overlap. Clinical relevance of genomic signatures of type 2 inflammation in chronic obstructive pulmonary disease. Am J Respir Crit Care Med. 2015;191(7):758-766. doi:10.1164/ rccm.201408-14580C

4. Singh D, Kolsum U, Brightling CE, et al. Eosinophilic inflammation in COPD: prevalence and clinical characteristics. Eur Respir J. 2014;44 (6):1697-1700. doi:10.1183/09031936.00162414

5. Le Rouzic O, Pichavant M, Frealle E, Guillon A, Si-Tahar M, Gosset P. Th17 cytokines: novel potential therapeutic targets for COPD pathogenesis and exacerbations. Eur Respir J. 2017;50 (4):1602434. doi:10.1183/13993003.02434-2016

6. Rovina N, Koutsoukou A, Koulouris NG. Inflammation and immune response in COPD: where do we stand? Mediators Inflamm. 2013;2013:413735. doi:10.1155/2013/413735

7. Imani S, Salimian J, Fu J, Ghanei M, Panahi Y. Th17/Treg-related cytokine imbalance in sulfur mustard exposed and stable chronic obstructive pulmonary (COPD) patients: correlation with disease activity. Immunopharmacol Immunotoxicol. 2016;38(4):270-280. doi:10.1080/08923973.2016.1188402

8. Wang H, Ying H, Wang S, et al. Imbalance of peripheral blood Th17 and Treg responses in patients with chronic obstructive pulmonary disease. Clin Respir J. 2015;9(3):330-341. doi:10.1111/crj.12147
9. Zou Y, Chen X, Liu J, et al. Serum IL-1beta and IL-17 levels in patients with COPD: associations with clinical parameters. Int J Chron Obstruct Pulmon Dis. 2017;12:1247-1254. doi:10.2147/COPD.S131877

10. Singh S, Verma SK, Kumar S, et al. Correlation of severity of chronic obstructive pulmonary disease with potential biomarkers. Immunol Lett. 2018;196:1-10. doi:10.1016/j.imlet.2018.01.004

11. Jiang S, Shan F, Zhang Y, Jiang L, Cheng Z. Increased serum IL-17 and decreased serum IL-10 and IL-35 levels correlate with the progression of COPD. Int $J$ Chron Obstruct Pulmon Dis. 2018;13:2483-2494. doi:10.2147/COPD.S167192

12. Suissa S, Ernst P, Hudson M. TNF-alpha antagonists and the prevention of hospitalisation for chronic obstructive pulmonary disease. Pulm Pharmacol Ther. 2008;21(1):234-238. doi:10.1016/j.pupt.2007.03.003

13. Rennard SI, Fogarty C, Kelsen S, et al. The safety and efficacy of infliximab in moderate to severe chronic obstructive pulmonary disease. Am J Respir Crit Care Med. 2007;175(9):926-934. doi:10. 1164/rccm.200607-995OC

14. Dentener MA, Creutzberg EC, Pennings HJ, Rijkers GT, Mercken E, Wouters EF. Effect of infliximab on local and systemic inflammation in chronic obstructive pulmonary disease: a pilot study. Respiration. 2008;76(3):275-282. doi:10.1159/000117386

15. Aaron SD, Vandemheen KL, Maltais F, et al. TNFalpha antagonists for acute exacerbations of COPD: a randomised double-blind controlled trial. Thorax. 2013;68(2):142-148. doi:10.1136/thoraxjnl2012-202432

16. Eich A, Urban V, Jutel M, et al. A randomized, placebo-controlled phase 2 trial of CNTO 6785 in chronic obstructive pulmonary disease. COPD. 2017;14(5):476-483. doi:10.1080/15412555.2017. 1335697

17. Vestbo J, Hurd SS, Agusti AG, et al. Global strategy for the diagnosis, management, and prevention of chronic obstructive pulmonary disease: GOLD executive summary. Am J Respir Crit Care Med. 2013;187(4):347-365. doi:10.1164/rccm.201204-0596PP

18. Pavord ID, Pizzichini MM, Pizzichini E, Hargreave FE. The use of induced sputum to investigate airway inflammation. Thorax. 1997;52 (6):498-501. doi:10.1136/thx.52.6.498

19. Kelly MM, Keatings V, Leigh R, et al. Analysis of fluid-phase mediators. Eur Respir J. 2002;20(Suppl Supplement 37):S24-S39. doi:10.1183/09031936.02.00002402

20. Lubin JH, Colt JS, Camann D, et al. Epidemiologic evaluation of measurement data in the presence of detection limits. Environ Health Perspect. 2004;112(17):1691-1696. doi:10.1289/ehp.7199

21. Hornung RW, Reed LD. Estimation of average concentration in the presence of nondetectable values. Appl Occup Environ Hyg. 1990;5 (1):46-51. doi:10.1080/1047322X.1990.10389587

22. Steinhaus H. Sur la division des corps matériels en parties. Bull Acad Polon Sci Cl III. 1956;4:801-804.

23. Ketchen DJ, Shook CL. The application of cluster analysis in strategic management research: an analysis and critique. Strategic Manage J. 1996;17(6):441-458. doi:10.1002/(SICI)1097-0266(199606) 17:6<441::AID-SMJ819>3.0.CO;2-G

24. Charrad M, Ghazzali N, Boiteau V, Niknafs A. NbClust: an $\mathrm{R}$ package for determining the relevant number of clusters in a data set. J Stat Softw. 2014;61(6):1-36. doi:10.18637/jss.v061.i06

25. Churg A, Wang RD, Tai H, Wang X, Xie C, Wright JL. Tumor necrosis factor-alpha drives $70 \%$ of cigarette smoke-induced emphysema in the mouse. Am J Respir Crit Care Med. 2004;170 (5):492-498. doi:10.1164/rccm.200404-5110C

26. Aaron SD, Angel JB, Lunau M, et al. Granulocyte inflammatory markers and airway infection during acute exacerbation of chronic obstructive pulmonary disease. Am J Respir Crit Care Med. 2001;163 (2):349-355. doi:10.1164/ajrccm.163.2.2003122

27. Bhatnagar S, Panguluri SK, Gupta SK, Dahiya S, Lundy RF, Kumar A. Tumor necrosis factor-alpha regulates distinct molecular pathways and gene networks in cultured skeletal muscle cells. PLoS One. 2010;5(10):e13262. doi:10.1371/journal.pone.0013262 
28. Ju CR, Chen RC. Serum myostatin levels and skeletal muscle wasting in chronic obstructive pulmonary disease. Respir Med. 2012;106 (1):102-108. doi:10.1016/j.rmed.2011.07.016

29. Tomoda K, Yoshikawa M, Itoh T, et al. Elevated circulating plasma adiponectin in underweight patients with COPD. Chest. 2007;132 (1):135-140. doi:10.1378/chest.07-0227

30. Calikoglu M, Sahin G, Unlu A, et al. Leptin and TNF-alpha levels in patients with chronic obstructive pulmonary disease and their relationship to nutritional parameters. Respiration. 2004;71(1):45-50. doi:10.1159/000075648

31. Hurst JR, Perera WR, Wilkinson TM, Donaldson GC, Wedzicha JA. Systemic and upper and lower airway inflammation at exacerbation of chronic obstructive pulmonary disease. Am J Respir Crit Care Med. 2006;173(1):71-78. doi:10.1164/rccm.200505-704OC

32. Pinto-Plata VM, Livnat G, Girish M, et al. Systemic cytokines, clinical and physiological changes in patients hospitalized for exacerbation of COPD. Chest. 2007;131(1):37-43. doi:10.1378/chest.06-0668

33. Doe C, Bafadhel M, Siddiqui S, et al. Expression of the $\mathrm{T}$ helper 17-associated cytokines IL-17A and IL-17F in asthma and COPD. Chest. 2010;138(5):1140-1147. doi:10.1378/chest.09-3058

34. Ponce-Gallegos MA, Ramirez-Venegas A, Falfan-Valencia R. Th17 profile in COPD exacerbations. Int J Chron Obstruct Pulmon Dis. 2017;12:1857-1865. doi:10.2147/COPD.S136592

35. Zhang X, Angkasekwinai P, Dong C, Tang H. Structure and function of interleukin-17 family cytokines. Protein Cell. 2011;2(1):26-40. doi:10.1007/s13238-011-1006-5

36. Rutz S, Eidenschenk C, Ouyang W. IL-22, not simply a Th17 cytokine. Immunol Rev. 2013;252(1):116-132. doi:10.1111/imr.12027

37. Zheng X, Zhang L, Chen J, Gu Y, Xu J, Ouyang Y. Dendritic cells and Th17/Treg ratio play critical roles in pathogenic process of chronic obstructive pulmonary disease. Biomed Pharmacother. 2018;108:1141-1151. doi:10.1016/j.biopha.2018.09.113

38. Roos AB, Sethi S, Nikota J, et al. IL-17A and the promotion of neutrophilia in acute exacerbation of chronic obstructive pulmonary disease. Am J Respir Crit Care Med. 2015;192(4):428-437. doi:10.1164/rccm.201409-16890C

39. Chang Y, Al-Alwan L, Audusseau S, et al. Genetic deletion of IL-17A reduces cigarette smoke-induced inflammation and alveolar type II cell apoptosis. Am J Physiol Lung Cell Mol Physiol. 2014;306 (2):L132-L143. doi:10.1152/ajplung.00111.2013

40. Yanagisawa H, Hashimoto M, Minagawa S, et al. Role of IL-17A in murine models of COPD airway disease. Am J Physiol Lung Cell Mol Physiol. 2017;312(1):L122-L130. doi:10.1152/ajplung.00301.2016

41. Kurimoto E, Miyahara N, Kanehiro A, et al. IL-17A is essential to the development of elastase-induced pulmonary inflammation and emphysema in mice. Respir Res. 2013;14(1):5. doi:10.1186/1465-9921-14-5

42. Sethi S, Murphy TF. Infection in the pathogenesis and course of chronic obstructive pulmonary disease. $N$ Engl J Med. 2008;359 (22):2355-2365. doi:10.1056/NEJMra0800353

43. Sharan R, Perez-Cruz M, Kervoaze G, et al. Interleukin-22 protects against non-typeable Haemophilus influenzae infection: alteration during chronic obstructive pulmonary disease. Mucosal Immunol. 2017;10(1):139-149. doi:10.1038/mi.2016.40
44. Pichavant M, Sharan R, Le Rouzic O, et al. IL-22 defect during streptococcus pneumoniae infection triggers exacerbation of chronic obstructive pulmonary disease. EBioMedicine. 2015;2(11):1686-1696. doi:10.1016/j.ebiom.2015.09.040

45. Le Rouzic O, Kone B, Kluza J, et al. Cigarette smoke alters the ability of human dendritic cells to promote anti-Streptococcus pneumoniae Th17 response. Respir Res. 2016;17(1):94. doi:10.1186/ s12931-016-0408-6

46. King PT, Lim S, Pick A, et al. Lung T-cell responses to nontypeable Haemophilus influenzae in patients with chronic obstructive pulmonary disease. J Allergy Clin Immunol. 2013;131(5):1314-1321.e14. doi:10.1016/j.jaci.2012.09.030

47. van de Kerkhof PC, Griffiths CE, Reich K, et al. Secukinumab long-term safety experience: a pooled analysis of 10 Phase II and III clinical studies in patients with moderate to severe plaque psoriasis. J Am Acad Dermatol. 2016;75(1):83-98.e4. doi:10.1016/j. jaad.2016.03.024

48. Andelid K, Tengvall S, Andersson A, et al. Systemic cytokine signaling via IL-17 in smokers with obstructive pulmonary disease: a link to bacterial colonization? Int J Chron Obstruct Pulmon Dis. 2015;10:689-702. doi:10.2147/COPD.S76273

49. Barczyk A, Pierzchala W, Sozanska E. Interleukin-17 in sputum correlates with airway hyperresponsiveness to methacholine. Respir Med. 2003;97(6):726-733. doi:10.1053/rmed.2003.1507

50. Zhang X, Zheng H, Zhang H, et al. Increased interleukin (IL)-8 and decreased IL-17 production in chronic obstructive pulmonary disease (COPD) provoked by cigarette smoke. Cytokine. 2011;56 (3):717-725. doi:10.1016/j.cyto.2011.09.010

51. Liao SX, Ding T, Rao XM, et al. Cigarette smoke affects dendritic cell maturation in the small airways of patients with chronic obstructive pulmonary disease. Mol Med Rep. 2015;11(1):219-225. doi:10.3892/mmr.2014.2759

52. Givi ME, Folkerts G, Wagenaar GT, Redegeld FA, Mortaz E. Cigarette smoke differentially modulates dendritic cell maturation and function in time. Respir Res. 2015;16(1):131. doi:10.1186/ s12931-015-0291-6

53. Solleiro-Villavicencio H, Quintana-Carrillo R, Falfan-Valencia R, Vargas-Rojas MI. Chronic obstructive pulmonary disease induced by exposure to biomass smoke is associated with a Th2 cytokine production profile. Clin Immunol. 2015;161(2):150-155. doi:10.1016/j.clim.2015.07.009

54. Ponce-Gallegos MA, Perez-Rubio G, Ambrocio-Ortiz E, et al. Genetic variants in IL17A and serum levels of IL-17A are associated with COPD related to tobacco smoking and biomass burning. Sci Rep. 2020;10(1):784. doi:10.1038/s41598-020-57606-6

55. Wang W, Deng G, Zhang G, et al. Genetic polymorphism rs8193036 of IL17A is associated with increased susceptibility to pulmonary tuberculosis in Chinese Han population. Cytokine. 2020;127:154956. doi:10.1016/j.cyto.2019.154956

56. Espinoza JL, Takami A, Nakata K, et al. A genetic variant in the IL-17 promoter is functionally associated with acute graft-versus-host disease after unrelated bone marrow transplantation. PLoS One. 2011;6(10):e26229. doi:10.1371/journal.pone.0026229

International Journal of Chronic Obstructive Pulmonary Disease

Dovepress

\section{Publish your work in this journal}

The International Journal of COPD is an international, peer-reviewed journal of therapeutics and pharmacology focusing on concise rapid reporting of clinical studies and reviews in COPD. Special focus is given to the pathophysiological processes underlying the disease, intervention programs, patient focused education, and self management protocols. This journal is indexed on PubMed Central, MedLine and CAS. The manuscript management system is completely online and includes a very quick and fair peer-review system, which is all easy to use. Visit http://www.dovepress.com/testimonials.php to read real quotes from published authors. 